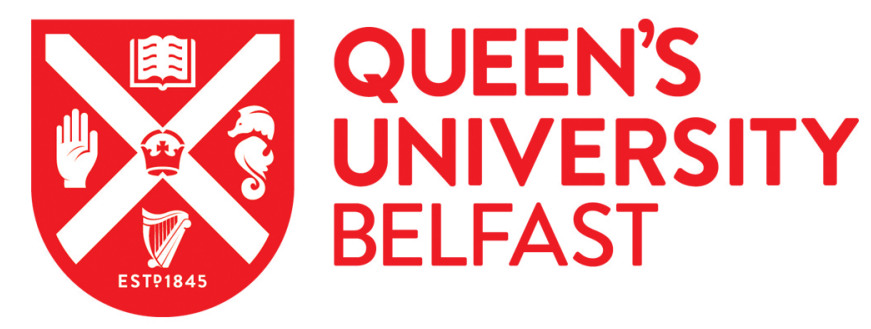

\title{
Are there different moral domains? Evidence from Mongolia
}

Berniunas, R., Dranseika, V., \& Sousa, P. (2016). Are there different moral domains? Evidence from Mongolia. Asian Journal of Social Psychology, 19(3), 275-282. https://doi.org/10.1111/ajsp.12133

Published in:

Asian Journal of Social Psychology

Document Version:

Early version, also known as pre-print

Queen's University Belfast - Research Portal:

Link to publication record in Queen's University Belfast Research Portal

Publisher rights

Copyright 2016 The Authors

This is the pre-peer reviewed version of the following article: Are there different moral domains? Evidence from Mongolia, which has been published in final form at [Link to final article using the DOI]. This article may be used for non-commercial purposes in accordance with Wiley Terms and Conditions for Self-Archiving

\section{General rights}

Copyright for the publications made accessible via the Queen's University Belfast Research Portal is retained by the author(s) and / or other copyright owners and it is a condition of accessing these publications that users recognise and abide by the legal requirements associated with these rights.

Take down policy

The Research Portal is Queen's institutional repository that provides access to Queen's research output. Every effort has been made to ensure that content in the Research Portal does not infringe any person's rights, or applicable UK laws. If you discover content in the Research Portal that you believe breaches copyright or violates any law, please contact openaccess@qub.ac.uk. 


\title{
Are there different moral domains? Evidence from Mongolia
}

\author{
Renatas Berniūnas, ${ }^{1 *}$ Vilius Dranseika ${ }^{1}$ and Paulo Sousa ${ }^{2}$ \\ ${ }^{1}$ Vilnius University, Lithuania and ${ }^{2}$ Queen's University Belfast, Northern Ireland
}

In this paper we report a study conducted in Mongolia on the scope of morality, that is, the extent to which people moralize different social domains. Following Turiel's moral-conventional task, we characterized moral transgressions (in contrast to conventional transgressions) in terms of two dimensions: authority independence and generality of scope. Differentmoral domains are then defined by grouping such moral transgressions in terms of their content (following Haidt's classification of morally relevant domains). There are four main results of the study. First, since all five Haidtian domains were moralized by the Mongolian participants, the study provides evidence in favour of pluralism about moral domains. However, the study also suggests that the domain of harm can be reduced to the fairness domain. Furthermore, although the strong claim about reduction of all moral domains to the domain of fairness seems not to hold, a significant number of participants did indicate considerations of fairness across domains. Finally, a significant amount of participants moralized conventional transgressions a la Turiel, but it did not reach a statistical significance.

Key words: Mongolia, social cognition, moral domains, moral psychology, moral/conventional task.

Q2 In a recent review, Henrich, Heine, \& Norenzayan (2010) argued that there is an obvious lack of cross-cultural perspective in studying human cognition, with researchers far too often relying on the so-called WEIRD (Western, Educated, Industrialized, Rich, and Democratic) sample to draw wide generalizations about cognitive universals. Similarly, there is an obvious lack of cross-cultural perspective in studying moral cognition (see also Sachdeva, Singh, \& Medin, 2011), although with some notable exceptions. ${ }^{1}$ Thus, heeding ecological validity, theoretical claims should be tested with a culturally more diverse sample. Therefore, the aim of this paper is to address debates about the scope of morality in the light of new evidence from Mongolia - an underrepresented cultural context.

Currently, there are several conflicting positions on the scope of morality, ranging from complete pluralists to complete monists. On the pluralist side, Haidt and his colleagues, following Shweder (e.g., Shweder et al., 1997), argued that there are at least five moral domains, comprising transgressions related to concerns about care/harm, fairness/cheating, loyalty/ betrayal, authority/subversion, and sanctity/degradation (Haidt \& Graham, 2007; for a recent theoretical review see Graham et al., 2013; for a recent methodological review

Correspondence: Renatas Berniūnas, Department of General Psychology, Faculty of Philosophy, Vilnius University, Universiteto str. 9/1, LT-01513 Vilnius, Lithuania. Email: renatasberniunas@ gmail.com

Received 9 November 2014; revision 2 December 2015; accepted 29 December 2015 see Graham et al., 2011; see also Sinnott-Armstrong \& Wheatley, 2012). The moral foundations theory (MFT), advocated by Haidt and his colleagues, argues that five types of concerns are salient across different cultures and different socio-economic groups, except to people from WEIRD societies, who mainly emphasize harm and fairness (see, e.g., Haidt et al., 1993). For example, Haidt and Graham (2007) demonstrate that American liberals mainly focus on harm and fairness, while American conservatives focus on all five transgressions. This pluralistic position was presented as an explicit criticism of Turiel and colleagues, who have argued that harm and fairness transgressions constitute two basic moral domains in human moral cognition (Nucci, 2001; Smetana, 1993; Tisak, 1995; Turiel, 1983). Thus, following Haidt's research, Mongolian participants, who are from a more traditionalistic no-WEIRD society, should be concerned with five types of moral transgressions, not only with harm and fairness (as Turiel argued).

However, two versions of moral monism recently emerged, which countered Haidt's pluralism by suggesting refined theoretical frameworks to account for the multitude of moral concerns. For instance, Gray and colleagues have argued that actually harmful transgressions constitute the basic moral domain, implying a completely monistic view of morality (Gray, Young, \& Waytz, 2012). They propose that "morality is essentially represented by a cognitive template that combines a perceived intentional agent with a perceived suffering patient' (p. 102), and this moral dyadic template (intentional agent and suffering patient) is 'a core feature of all immoral acts' (p. 107). Consequently, there are no harmless moral transgressions in folk moral cognition, 
simply because the dyadic template compels 'the mind to perceive victims even when they are objectively absent' (Gray, Schein, \& Ward, 2014, p. 1).

On the other hand, Sousa and colleagues have argued for a deflationary view of the morality of harm, in which harmful transgressions are seen as moral transgressions only if they are seen as involving injustice, that is, harmful transgressions are reducible to fairness transgressions (see Sousa, 2009; Sousa, Holbrook, \& Piazza, 2009; Piazza, Sousa, \& Holbrook, 2013; Sousa \& Piazza, 2014). In other words, not all harmful actions are moral transgressions (e.g., a dentist is causing you pain in order to fix your teeth), only those harmful actions that are unjustified (that is, involve unjust or unfair treatment) are categorized as moral transgressions (e.g., a dentist is causing you pain to obtain your golden tooth). Moreover, questioning Haidt's position, Sousa and colleagues have argued that more evidence is needed to show that other normative domains are moralized in terms of the moral signature and, therefore, whether there are other moral domains in this specific sense remains an open empirical questions. Finally, also questioning Haidt's position, Baumard and colleagues have argued more radically that many of Haidt's domains are not clearly seen as dissociated from the domain of fairness, which opens the possibility that these domains are moralized only insofar as they involve fairness considerations (Baumard, André, \& Sperber, 2013; Baumard \& Sperber, 2012; Sperber \& Baumard, 2012; see also Fraser, 2012). Thus, taken together, Sousa, Baumard and their colleagues suggest an alternative fairness-based monistic view. According to both monistic positions, then, it could be suggested that even if Mongolians express a concern about a variety of transgressions ( $\grave{l}$ la Haidt), it is quite possible that these different transgression are moralized only insofar as they involve fairness (Sousa and Baumard) or harm (Gray and colleagues) considerations.

Before proceeding to the study about the scope of moral considerations among Mongolian participants, we will briefly delineate a conceptual framework that will be employed in this paper. Our discussion concerns normative judgments - that is, judgments to the effect that an action is forbidden and that pursuing the action is wrong (or, equivalently, is a transgression). It should be noted that in the current literature, while delineating the moral domain, the term 'moral' has been used in two basic senses (see Sousa \& Piazza, 2014). In one sense, the emphasis is on a type of normative content. Indeed, the above discussed positions talk about the 'moral' in this sense. In another sense, the emphasis is on a specific type of normative conviction - that is, moral transgressions evoke a strong evaluative conviction that an action is wrong, no matter what is the normative content. Importantly, there is little agreement on what counts as a relevant normative content (e.g., are there five normative domains or just one?), and how to characterize the strong normative conviction in moral judgments. Thus, for the purposes of our current research, we will specify the normative content as moral domain with normative conviction. Specifically, following the tradition of Turiel (e.g., Turiel, 1983), we characterize the normative conviction specifying moral transgressions in contraposition to the normative conviction specifying conventional transgressions (like eating with one's fingers), in terms of two dimensions: while moral transgressions are seen as authority independent (i.e., their wrongness is not cancellable by the decision of any authority) and general in scope (i.e., their wrongness extends to different places and times), conventional transgressions are seen as authority dependent and/or local in scope (for alternative ways of characterizing the strong normative conviction that specifies moral transgressions, see Goodwin \& Darley, 2008; Sripada \& Stich, 2006; Skitka, Bauman, \& Sargis, 2005; Tetlock, 2003). We shall call the criteria of authority independence and generality the 'moral signature' (see Kelly, Stich, Haley, Eng, \& Fessler, 2007; Sousa et al., 2009).

From this perspective, the claim that there are different moral domains is tantamount to the claim that ordinary people can have the above strong normative conviction (i.e., 'moral signature') in relation to different types of normative contents (e.g., unjustified harm, unfair treatment in cooperation, and expression of disloyalty to a group, disrespect towards authority, or purity transgressions). In other words, each separate type of normative content that evokes the moral signature is to be considered a distinct moral domain. Conversely, from this perspective, there are two ways of showing that a normative domain is not a distinct moral domain. One may show that the normative domain does not evoke the moral signature, and hence is not a moral domain at all. Alternatively, one may show that although the normative domain apparently evokes the moral signature, it is another type of normative content that is doing the job, and hence that the supposed normative domain is not a distinct moral domain (see Turiel's classical argument against Shweder; Turiel, Killen, \& Helwig, 1987; see also Fraser, 2012). For example, one may show that purity transgressions evoke the moral signature only when they are public transgressions, and that the normative content that makes these transgressions evoke the moral signature is related to the fact that they are offensive, and therefore harmful. In other words, one may argue that purity transgressions qua moral transgressions are reducible to harmful transgressions (see Royzman, Leeman, \& Baron, 2009).

\section{Theoretical predictions}

Our research design is a revised version of the moralconventional task that was employed by Turiel and his colleagues (Nucci, 2001; Smetana, 1993; Tisak, 1995; Turiel, 1983). Specifically, the current version was devised to probe 
the claims concerning the existence of different moral domains put forward by the aforementioned theoretical positions in the Mongolian context. According to current design, each separate type of normative content that evokes the moral signature is to be considered a distinct moral domain. However, we also took into consideration the monistic possibility, for example, when fairness-based normative content is somehow implied in other normative domains thereby evoking the moral signature. Taken together, we put forward three kinds of predictions that stem from different theoretical positions, and test them in the Mongolian context.

First, if Mongolian participants evoke the moral signature in all five domains, this is evidence in favour of Haidt's theory of moral foundations, since theory predicts that non-WEIRD cultures are concerned with five types of moral transgressions. Second, if participants evoke the moral signature in the conventional domain, this is evidence against the moral/ conventional distinction as traditionally conceived by Turiel and colleagues. Third, if participants imply some kind of fairness considerations in the harm domain, this is evidence consistent with the deflationary view of harm (as Sousa and colleagues argue). If fairness is consistently implied in all domains that are moralized, this is evidence consistent with the strong claim that normative domains are moralized only insofar as they involve fairness considerations (as Baumard and colleagues argue). Conversely, if participants imply some kind of harm in other domains, this is evidence consistent with harm-based monism (as Gray and colleagues argue).

\section{Methods}

\section{Cultural context}

The study was conducted in Ulan Bator, the capital city of Mongolia. The country is situated between China and the Siberian parts of Russia. For the most part, Mongolians were nomadic herders, pasturing horses, sheep, yaks, and other animals in the steppes. Historically, shamanism was the dominant form of religion, but since the end of the 16th century the majority of Mongolians converted to the Tibetan style of Buddhism. In the 20th century, Mongolia was one of the first Soviet countries to undergo rapid social changes and urbanization. Now, an independent democratic republic, Mongolia has a fast growing economic centre in Ulan Bator (with over a million inhabitants, and with a population of 2.9 million in the country as a whole), while a significant proportion of the population outside of bigger towns still practice a nomadic life style in steppes. According to the last National Census in 2010, approximately 53\% of the population are Buddhists, 3\% Shamanists, 3\% Muslims (mostly among the Kazakh minority), and 39\% nonreligious.

\section{Participants}

Because a proper lab environment and recruitment system were not possible, we relied on convenience sampling. Two Mongolian assistants helped to recruit 340 participants at the National University of Mongolia, University of Science and Technology, and University of Humanities. Participants were not paid and were asked to complete voluntarily a study questionnaire in the auditoriums between the lectures. Participants who agreed to participate but did not answer the primary study questions were excluded from the study. This way, 74 participants were excluded, leaving a total of 266 participants (65\% female; mean age 19). Religious affiliation was distributed as follows: Buddhists (44\%), Shamanists (12\%), both Buddhist and Shamanists (7\%), non-religious (34\%), other (4\%).

\section{Materials and procedure}

There were six conditions in the study, each with two separate vignettes describing what an agent did in a specific situation. Our main aim was to test recent theoretical claims about the scope of moral domains. Thus, five conditions each involved actions corresponding to one of the five Haidtian moral domains, and one condition involved actions corresponding to the conventional domain, as conceived by Turiel (see Appendix for the conditions with their two respective vignettes). ${ }^{2}$ The first author of this paper spent one year in Mongolia doing field research, using his familiarity with the culture to validate the content of each vignette. In addition, Mongolian assistants read and commented on the comprehensibility and cultural relevance of the stories and questions. The stories conveyed rather typical characters with typical Mongolian names in recognizable settings. ${ }^{3}$

Each participant was randomly assigned to one of the six conditions of the study, reading its two separate vignettes and answering their related questions (the order of presentation of the two vignettes was counterbalanced). The questions for each vignette were as follows, in fixed order. First, the participants were asked whether they consider the action of the scenario a transgression: 'in your personal opinion, is it wrong that [agent] did [action] in this situation?' ('Yes/No'). If the answer was positive ('Yes'), the participant was presented with the two moral signature probes (i.e., authority dependence and generalizability): (1) 'suppose that an authority that you trust and respect said that in this situation it is not wrong for agent $A$ to do $X$ '; (2) 'suppose that agent $A$ lived in a country where everyone thinks that in this situation it is not wrong to do $X^{\prime}$. For each moral signature probe, participants had to indicate whether they agreed that the action $X$ would still be wrong under such circumstances (an indication of agreement in both probes constituted the 'moral signature'). After the moral signature probes, participants answered two explicit questions about whether 
the action caused harm to someone ('hurt someone physically or psychologically') or was unfair to someone. Now, if the answer to the initial transgression question was negative ('No'), the participant was asked to skip the moral probes and move directly to the other two questions. In relation to these two questions, participants were also asked to indicate who was subjected to harm or injustice. In relation to the remaining questions, participants were also requested to provide a brief justification for their answers. For these open questions, participants wrote down their responses.

\section{Results}

T1 Table 1 represents the number of participants evincing the response patterns in each of the scenarios. Columns 'NO' and 'YES' represent the number of participants who answered 'no' (i.e., not wrong) or 'yes' (i.e., wrong) to the transgression question. The remaining columns represent the number of participants evincing each of the four possible response patterns of 'yes' or 'no' answers to the moral signature probes (the first 'YES' or 'NO' is related to the authority dependence probe; the second 'YES' or 'NO' is related to the generalizability probe), with the 'YES-YES' column showing the participants who evoked the moral signature. A large amount of participants answered 'not-wrong' in some scenarios - in particular, Authority (Dalai Lama) and In-group (Citizenship). Of the remaining participants, who answered 'wrong', a rather high percentage evinced the moral signature in most scenarios.

T2 Table 2 shows one-sample Chi-Square tests against chance on the percentage of participants answering wrong ('Yes') to the transgression probe and on the percentage of participants evoking the moral signature (i.e., the 'Yes-Yes' response pattern). The results indicate that, except for Authority (Dalai) and In-group (Citizenship), wrongness answers were significantly above chance in all scenarios. Moreover, moral signature answers were significantly above chance in all scenarios, except for the conventional ones, where they approached significance. Effect sizes varied from medium to large.

It has been shown in previous research that religiosity has a strong influence on people's understanding of moral issues (e.g., Graham et al., 2013). In respect to moral signature responses, we compared all religious participants $(66 \%)$ with non-religious participants (34\%), across all domains. Each participant had two moral signature responses, thus there were three possible patterns of the overall moral signature responses: 0 , no signature response; 1 , one signature response; 2 , two signature responses. Two samples Chi-Square test showed that, overall, there was no significant difference between religious and non-religious participants, $x^{2}(2,250)$ $=0.592, p=0.744$. The only potentially moderating role of religiosity was in responses to the Authority (Dalai) transgression question (more in the Discussion section).

Furthermore, Table 2 shows that moral signature answers were significantly above chance in all scenarios, except for the conventional ones. However, the latter scenarios approached significance. For that, we compared moral signature responses between all five moral domains and the conventional domain. As in the previous analyses, two moral signature values were combined. Interestingly, two sample Chi-Square tests showed that there was a statistically significant difference between the harm and fairness domains, and the conventional domain $\left(x^{2}(2,81)=13.447\right.$, $p=0.001$ and $x^{2}(2,90)=6.711, p=0.035$, respectively). But there was no significant difference between the authority, in-group and purity domains, and the conventional domain

Table 1 Number of participants for each response pattern

\begin{tabular}{|c|c|c|c|c|c|c|c|}
\hline \multirow[t]{2}{*}{ Scenarios } & \multirow[t]{2}{*}{ Total } & \multicolumn{2}{|c|}{$\begin{array}{c}\text { Transgression } \\
\text { Probe }\end{array}$} & \multicolumn{4}{|c|}{ Moral Signature Probes } \\
\hline & & NO & YES & YES-YES & YES-NO & NO-YES & NO-NO \\
\hline Harm (Hitting) & 43 & 2 & 41 & 34 & 7 & 0 & 0 \\
\hline Harm (Insulting) & & 3 & 40 & 35 & 5 & 0 & 0 \\
\hline Fairness (Cheating) & 51 & 0 & 51 & 40 & 10 & 0 & 1 \\
\hline Fairness (Stealing) & & 3 & 48 & 35 & 12 & 0 & 1 \\
\hline Authority (Flag) & 42 & 2 & 40 & 34 & 6 & 0 & 0 \\
\hline Authority (Dalai) & & 20 & 22 & 17 & 1 & 0 & 4 \\
\hline Ingroup (Citizen) & 42 & 21 & 21 & 15 & 5 & 0 & 1 \\
\hline Ingroup (Betrayal) & & 9 & 33 & 24 & 6 & 0 & 3 \\
\hline Purity (Dog) & 47 & 10 & 37 & 25 & 9 & 2 & 1 \\
\hline Purity (Temple) & & 12 & 35 & 29 & 5 & 0 & 1 \\
\hline Convention (Hands) & 41 & 14 & 27 & 18 & 9 & 0 & 0 \\
\hline Convention ("You”) & & 6 & 35 & 23 & 12 & 0 & 0 \\
\hline
\end{tabular}


Table 2 One sample Chi-Square tests against the chance

\begin{tabular}{|c|c|c|c|c|}
\hline \multirow[t]{2}{*}{ Scenarios } & \multicolumn{2}{|c|}{ Wrong } & \multicolumn{2}{|c|}{ Moral Signature } \\
\hline & Significance $(p)$ & Effect size $\left(r_{\phi}\right)$ & Significance $(p)$ & Effect size $\left(r_{\phi}\right)$ \\
\hline Harm (Hitting) & .000 & .907 & .000 & .659 \\
\hline Harm (Insulting) & .000 & .861 & .000 & .750 \\
\hline Fairness (Cheating)* & - & - & .000 & .569 \\
\hline Fairness (Stealing) & .000 & .882 & .001 & .458 \\
\hline Authority (Flag) & .000 & .905 & .000 & .700 \\
\hline Authority (Dalai) & .758 & .048 & .011 & .545 \\
\hline Ingroup (Citizenship) & 1 & 0 & .050 & .429 \\
\hline Ingroup (Betrayal) & .000 & .571 & .009 & .454 \\
\hline Purity (Dog) & .000 & .575 & .033 & .351 \\
\hline Purity (Temple) & .001 & .489 & .000 & .657 \\
\hline Conventional (Hands) & .042 & .317 & .083 & .333 \\
\hline Conventional ("You”) & .000 & .707 & .063 & .314 \\
\hline
\end{tabular}

Note. * All participants (100\%) responded that cheating is wrong.

$\left(x^{2}(2,79)=2.117, p=0.347 ; x^{2}(2,75)=3.083, p=0.214 ;\right.$ $x^{2}(2,84)=2.106, p=0.349$; respectively).

T3 Table 3 concerns only those participants who evoked the moral signature. It shows the number of participants in each scenario evincing each of the four possible response patterns to follow-up questions about the presence of harm $(\mathrm{H})$ and/or unfairness (F). ${ }^{4}$ In the domains of harm and fairness, almost all participants indicated the presence of harm and fairness considerations (i.e., $+\mathrm{H}+\mathrm{F}$ ), and almost no participant indicated their joint absence (i.e., -H-F). According to one proposal (see Sousa \& Piazza, 2014), there is a good theoretical reason to reduce harm domain to fairness domain, that is, harmful actions can be conceptualized as moral

Table 3 Number of participants showing each of the four possible response patterns to harm and fairness questions

\begin{tabular}{lccccr}
\hline Scenarios & Total & $+\mathbf{H}+\mathbf{F}$ & $\mathbf{+ H}-\mathbf{F}$ & $\mathbf{- H}+\mathbf{F}$ & $\mathbf{- H}-\mathbf{F}$ \\
\hline Harm (Hitting) & 34 & 34 & 0 & 0 & 0 \\
Harm (Insulting) & 35 & 33 & 1 & 0 & 1 \\
Fairness (Cheating) & 39 & 38 & 0 & 0 & 1 \\
Fairness (Stealing) & 35 & 31 & 1 & 1 & 2 \\
Authority (Flag) & 30 & 9 & 3 & 4 & 14 \\
Authority (Dalai) & 17 & 9 & 0 & 0 & 8 \\
Ingroup (Citizenship) & 13 & 4 & 3 & 0 & 6 \\
Ingroup (Betrayal) & 22 & 16 & 0 & 5 & 1 \\
Purity (Dog) & 23 & 12 & 2 & 6 & 3 \\
Purity (Temple) & 28 & 18 & 4 & 3 & 3 \\
Conventional (Hands) & 17 & 2 & 2 & 0 & 13 \\
Conventional ("You") & 23 & 13 & 2 & 2 & 6 \\
\hline
\end{tabular}

Note. $+\mathrm{H}+\mathrm{F}$ (both harm and fairness present), $+\mathrm{H}-\mathrm{F}$ (only harm present), $-\mathrm{H}+\mathrm{F}$ (only fairness present), - $\mathrm{H}-\mathrm{F}$ (neither harm nor fairness present). transgression only when fairness considerations are involved. Our results do not provide a direct evidence for this contention since an equally large proportion of participants indicated that harm and/or unfairness was present $(+\mathrm{H}+\mathrm{F}$ ). One thing is clear: these are very closely related concepts, further empirical research is needed to disentangle their relationship.

In the remaining scenarios, responses were much more varied, departing from this clear-cut pattern to a greater or lesser extent. It is worth noticing that, in most of these remaining scenarios, a large proportion of participants still indicated that harm andlor fairness was present (i.e., evinced $+\mathrm{H}+\mathrm{F},+\mathrm{H}-\mathrm{F}$, or $-\mathrm{H}+\mathrm{F}$ ). Now, to what extent these concepts, jointly or separately, underlie other domains is still an open question. However, taken together and across scenarios, the correlation between fairness and the moral signature responses was weak but significant, whereas the correlation between harm and the moral signature was even weaker and not significant $-r_{\phi}(412)=0.15, p=0.003$ and $r_{\phi}(412)=0.08, p=0.107$, respectively. The correlation between harm and fairness was strong and significant $-r_{\phi}$ $(412)=0.65, p=0.000$. A binary logistic regression using fairness and harm as predictors and the moral signature as the outcome variable revealed a main effect of fairness ( $B=-1.03$, Wald $=6.55, p=.010)$, but neither a main effect of harm nor an interaction $(B=-.18$, Wald $=.14, p=.704$ and $B=.58$, Wald $=.78, p=.376$, respectively). ${ }^{5}$

\section{Discussion and conclusions}

Before discussing how the results speak to the theoretical predictions we delineated, it is worth addressing the fact that, in relation to the Authority (Dalai Lama) and In-group 
(Citizenship) scenarios, approximately half of the participants answered 'not wrong'. One possible explanation for the Authority (Dalai Lama) scenario is that non-religious participants (34\%), in contrast to religious participants, took Dalai Lama as a less important authority figure and therefore answered that there is nothing wrong with practising shooting at his portrait because, as many responded, 'it is just a portrait'. Indeed, while $61 \%$ of non-religious participants thought it was not wrong to use his portrait for shooting, $68 \%$ of all religious participants (of which $71 \%$ were Buddhists) thought it was wrong because, as many responded, 'he should respect [Dalai Lama]'. As for the In-group (Citizenship) scenario, one possible explanation could be that our sample consists mainly of young students. Interestingly, even though in Mongolia Chinese are very often portrayed in negative terms, and marriage to a Chinese man is sometimes considered as a kind of treason, many students explained it as a 'personal matter'. Nevertheless, the overwhelming majority of participants who did consider those actions to be wrong, consistently evoked the moral signature - 17 out of 22 in the Authority (Dalai Lama) and 15 out of 21 in the In-group (Citizenship) scenarios, respectively.

Moreover, although we did not provide an analysis of participants' justifications to their 'Yes' or 'No' answers, we would like to point out a problem clearly indicated by these justifications in relation to the generalizability probe in the context of the Authority (Flag) scenario. Contrary to our intention, some participants may have interpreted the generalizability probe in this context as if the target agent was still a Mongolian using the Mongolian flag to clean the toilet, but in another country. Thus, the high percentage of participants evoking the moral signature in this scenario has to be interpreted with caution.

Having said that, the results show that in all five Haidtian domains a significant amount of participants who responded 'yes' to the transgression probe evoked the moral signature, suggesting that Mongolians are inclined to moralize all these domains, which would constitute evidence in favour of moral pluralism. Something Haidt predicted would be the case with non-WEIRD cultures.

Reductionists may counter-argue, however. First, there is the issue of whether the harm domain can be reduced to the domain of fairness, as far as morality is concerned. Our results from follow-up questions showed a strong correlation between concerns with harm and fairness. However, concerns of fairness not only correlated with the moral signature but also were an independent predictor of it, while concerns of harm neither predicted nor mediated the moral signature response pattern. This is some, but not conclusive, evidence in favour of the deflationary view of harm advocated by Sousa and colleagues, and against not only Turiel, Haidt and their colleagues, who distinguish the domains of harm and fairness, but also against monists like Gray and colleagues, who would like to reduce all morality to a fundamental concern with harm. However, more direct evidence is needed to rule out the possibility of harm-based reduction or the possibility that indeed these are two separate domains.

Second, there is the issue of whether the domains of Ingroup, Authority and Purity are reducible to the domain of fairness, namely, whether a concern with fairness is what leads participants to evoke the moral signature in these domains. One may argue that a large amount of participants did not have a concern with fairness while evoking the moral signature, which is evidence for pluralism and against the kind of monism advocated by Baumard. However, a concern with fairness was still substantial in these domains. In Purity (temple) 21 out of 28 participants, in Purity (dog) 18 out of 23 participants, in In-group (Betrayal) 21 out of 22 participants expressed a concern with fairness (see Table 3 ). In the remaining scenarios, only about half of the participants expressed such a concern, but these scenarios are somewhat more problematic. Still, even though some scenarios (notably, both Authority and In-group (Citizenship) scenario) did not elicit fairness considerations to a significant number of participants, this does not rule out the possibility that an implicitly held concept of fairness facilitates various moral judgments. Thus, the take-home message is that Haidt was right to point out that non-WEIRD cultures are concerned with a wider array of moral transgressions (as our Mongolian sample shows), but perhaps is not completely right about the psychological processes that deliver it. The psychology of fairness, as Sousa and Baumard argue, could be, to some significant degree, at the heart of this process. Further work, with new methodology and with varied sample, should shed some light on particular details of these psychological processes.

Finally, we also wanted to test whether Mongolians conceptualize certain transgressions as conventional à la Turiel. Our results indicate that participants evoked the moral signature in the conventional domain much less frequently, showing that in a way Turiel is correct. However, the number of participants who evoked the moral signature was still relatively high in both Conventional (hands) and Conventional ('you'). It seems that a non-negligible number of Mongolian participants think that the actions of eating noodles with bare hands and addressing professors with informal 'you' are moral transgressions. What kind of normative content could lead to such a response? Is it just a concern with etiquette? In relation to Conventional ('you'), because 17 out 23 participants expressed a concern with fairness and/or harm (see Table 3), it is possible that most participants consider this type of action to be unjustifiably offensive, which, assuming the deflationary view of the morality of harm, would be consistent with fairness monism (see also Turiel's (1983) discussion of the secondorder moral significance that conventional transgressions may acquire). However, some participants in Conventional ('you') and most participants in Conventional (hands) did not express any concern with fairness or harm. This may be explained in terms of disrespect of authority (i.e., addressing 
professors with informal 'you' compromises an important hierarchical relationship) and purity (i.e., eating noodles with bare hands is indecent and disgusting). In other words, what is a convention to Westerners (Turiel's typical sample), might not be a convention to Mongolians, so it can evoke a much stronger normative reaction, that is, the moral signature (see Shweder et al., 1997, for similar observation among Orissa in India).

\section{Endnotes}

1. For instance, studies with children from orthodox Jewish and Amish communities by Nucci and Turiel (1993), with Brazilian adults by Haidt, Koller, and Dias (1993), Indian adults by
Shweder, Much, Mahapatra, and Park (1997), or Hong Kong Chinese participants by Yau and Smetana (2003).

2. For the original material in Mongolian, contact the first author.

3. As for the prototypicallity of transgressions in each domain, for the sake of the argument, we characterized each domain by using Haidt's and his colleagues descriptions of what content makes each domain (see, for instance, Graham et al., 2011). Of course, we acknowledge a need for separate qualitative research that would help to determine people's own prototypical examples of moral transgression.

4. Total numbers do not correspond exactly to related total numbers in Table 1 because of some missing values.

5. The results here should be interpreted with caution, since the assumption of independence is not completely met, given that we consider the paired scenarios of each domain as two separate cases, when in fact they are not.

\section{References}

Baumard, N. \& Sperber, D. (2012). Evolutionary and cognitive anthropology. In: D. Fassin, (Ed.) A Companion to Moral Anthropology,

(pp. 611-627). Wiley-Blackwell.

Baumard, N., André, J. B. \& Sperber, D. (2013). A mutualistic approach to morality: The evolution of fairness by partner choice. Behavioral and Brain Sciences, 36(1), 59-78. doi: http://dx. doi.org/10.1017/S0140525X12000672

Fraser, B. (2012). The nature of moral judgements and the extent of the moral domain. Philosophical Explorations, 15(1), 1-16. doi: http://dx.doi.org/10.1080/ 13869795.2012.647356

Goodwin, G. P. \& Darley, J. M. (2008). The psychology of meta-ethics: Exploring objectivism. Cogni'tion, 106, 1339-1366. doi: http:// dx.doi.org/10.1016/j.cognition.2007.06.007

Graham, J., Nosek, B. A., Haidt, J., Iyer, R., Koleva, S. \& Ditto, P. H. (2011). Mapping the moral domain. Journal of Personality and Social Psychology, 101(2), 366-385. doi: http://dx.doi.org/10.1037/a0021847

Graham, J., Haidt, J., Koleva, S., Motyl, M., Iyer, R., Wojcik, S. et al. (2013). Moral foundations theory: The pragmatic validity of moral pluralism. Advances in Experimental Social Psychology, 47, 55-130. doi: http://dx.doi.org/ 10.1016/b978-0-12-407236-7.00002-4

Gray, K., Young, L. \& Waytz, A. (2012). Mind perception is the essence of morality. Psychological Inquiry, 23(2), 101-124. doi: http://dx.doi.org/10.1080/ 1047840X.2012.651387

Gray, K., Schein, C. \& Ward, A. F. (2014). The myth of harmless wrongs in moral cognition: automatic dyadic completion from sin to suffering. Journal of Experimental Psychology: General, Mar 17, doi: http://dx. doi.org/10.1037/a0036149

Haidt, J. \& Graham, J. (2007). When morality opposes justice: Conservatives have moral intuitions that liberals may not recognize. Social Justice Research, 20(1), 98-116. doi: http://dx.doi.org/10,1007/s11211-007-0034-z

Haidt, J., Koller, S. H. \& Dias, M. G. (1993). Affect, culture, and morality, or is it wrong to eat your dog? Journal of Personality and Social Psychology, 65(4), 613-628. doi: http://dx.doi. org/10.1037/0022-3514.65.4.613

Kelly, D., Stich, S., Haley, K. J., Eng, S. J. \& Fessler, D. M. (2007). Harm, affect, and the moral/conventional distinction. Mind \& Language, 22(2), 117-131. doi: http://dx.doi. org/10.1111/j.1468-0017.2007.00302.x

Nucci, L. P. (2001). Education in the Moral Domain. Cambridge University Press. doi: http://dx.doi.org/10.1017/cbo9780511605987

Nucci, L. \& Turiel, E. (1993). God's word, religious rules, and their relation to Christian and Jewish children's concepts of morality. Child Development, 64 (5): 1475-1491. doi: http://dx.doi.org/10.2307/1131547

Piazza, J., Sousa, P. \& Holbrook, C. (2013). Authority dependence and judgments of utilitarian harm. Cognition, 128, 261-270. doi: http://dx.doi.org/10.1016/j.cognition. 2013.05.001

Royzman, E., Leeman, R. F. \& Baron, J. (2009). Unsentimental ethics: Towards a contentspecific account of the moral-conventional distinction. Cognition, 112, 159-174. doi: http://dx.doi.org/10.1016/j.cognition.2009.04. 004

Sachdeva, S., Singh, P. \& Medin, D. (2011) Culture and the quest for universal principles in moral reasoning. International Journal of Psychology, 46(3), 161-176. doi: http://dx. doi.org/10.1080/00207594.2011.568486

Shweder, R. A., Much, N. C., Mahapatra, M. \& Park, L. (1997). The 'big three' of morality (autonomy, community, and divinity), and the 'big three' explanations of suffering. In: A. Brandt \& P. Rozin (Eds.), Morality and Health, (pp. 119-169). New York: Routledge. Sinnott-Armstrong, W. \& Wheatley, T. (2012). The disunity of morality and why it matters to philosophy. The Monist, 95(3), 355-377. doi: http://dx.doi.org/10.5840/monist201295319

Skitka, L. J., Bauman, Ch. W. \& Sargis, E. G. (2005). Moral conviction: Another contributor to attitude strength or something more? Journal of Personality and Social Psychology, 88(6), 895-917. doi: http://dx.doi.org/ 10.1037/0022-3514.88.6.895

Smetana, J. (1993). Understanding of social rules. In M. Bennett (Ed.) The Development of Social Cognition: The Child as Psychologist. New York: Guilford Press.

Sousa, P. (2009). On testing the moral law. Mind \& Language, 24, 209-234. doi: http://dx.doi. org/10.1111/j.1468-0017.2008.01360.x

Sousa, P. \& Piazza, J. (2014). Harmful transgressions qua moral transgressions: A deflationary view. Thinking \& Reasoning, 20 (1), 99-128 doi: http://dx.doi.org/10.1080/ 13546783.2013.834845

Sousa, P., Holbrook, C. \& Piazza, J. (2009). The morality of harm. Cognition, 113, 80-92. doi: http://dx.doi.org/10.1016/j. cognition.2009.06.015

Sperber, D. \& Baumard, N. (2012). Moral reputation: an evolutionary and cognitive perspective. Mind \& Language, 27(5), 495518. doi: http://dx.doi.org/10.1111/mila.12000 
Sripada, C. \& Stich, S. (2006). A framework for the psychology of norms. In: P. Carruthers, S. Laurence \& S. Stich (Eds.), The Innate Mind, Volume 2: Culture and Cognition, (pp. 280-301). Oxford University Press. doi: http://dx.doi.org/10.1093/acprof: oso/9780195310139.003.0017

Tetlock, P. E. (2003). Thinking the unthinkable: Sacred values and taboo cognitions. Trends in Cognitive Sciences, 7(7), 320-324. doi: http:// dx.doi.org/10.1016/S1364-6613(03)00135-9
Tisak, M. (1995). Domains of social reasoning and beyond. In: R. Vasta (Ed.) Annals of Child Development (Vol. 11, pp. 95-130). London: Jessica Kingsley.

Turiel, E. (1983). The Development of Social Knowledge: Morality and Convention. Cambridge, England: Cambridge University Press.

Turiel, E., Killen, M. \& Helwig, C. C. (1987). Morality: Its structure, function, and vagaries. In: J. Kagan \& S. Lamb (Eds.), The
Emergence of Morality in Young Children, (pp. 155-243). Chicago: University of Chicago Press.

Yau, J. \& Smetana J. (2003). Conceptions of moral, social-conventional, and personal events among Chinese preschoolers in Hong Kong. Child Development, 74, 647-658. doi: http://dx.doi.org/10.1111/1467-8624.00560

\section{APPENDIX}

Harm (Hitting)

Harm (Insulting)

Fairness(Cheating)

Fairness (Stealing)

Authority (Flag)

Authority (Dalai)

In-group (Citizenship)

In-group (Betrayal)

Purity (Dog)

Purity (Temple)

Conventional (Hands)

Conventional ('You')
Munkh-Erdene is sitting on a bench and is very bored. One unfamiliar boy passes by and Munkh-Erdene punches him on his face very hard, just for fun.

A new girl moved to a local town. Otgonbayar didn't like her dress, so he insulted the girl by calling her ugly.

Nergui borrowed a big sum of money from his good friend to buy a car. He bought the car and never paid back his friend.

While driving in the steppes, Gantulga noticed a sheep that was a bit apart from a nearby herd. The herders were in the ger, so he grabbed that sheep and drove away.

Byamba is cleaning out her closet, and finds her old Mongolian flag. She doesn't want the flag anymore, so she cuts it up into pieces and uses the rags to clean the toilet.

Ganzorig is a skilled archer. One day he decides to practise on a painted target. He goes to a remote place in the steppes but, when he is about to start practising, he finds out that he left his target at home. However, in his bag Ganzorig also has a picture of the Dalai Lama. The picture seems to be the right size to serve as a target, so he practises by shooting at the Dalai Lama picture.

Altantsetseg went to China to study. Over several years she learned the language, married to a Chinese man and renounced Mongolian citizenship.

Batbayar and other men from his tribe went to sell some horses near the border with Russia. Suddenly, several Russian armed men from that region appeared. Even though Batbayar had a gun as well, he was scared and ran way, leaving his fellow tribesmen to fight alone.

Erdene's dog was killed by a car in front of his house. He had heard that dog meat is delicious, so he cut up the dog's body, cooked it and ate it while he was alone.

Ganbold was walking in a small town. He had a terrible stomachache all day and he needed to relieve himself immediately. Then he saw a small Buddhist temple. Nobody was around, so he rushed inside the temple and relieved himself there.

It is lunch time at high school. Enkhjargal bought some tsuivan at the local canteen and ate it with her hands.

Bolormaa is studying at university. When she meets her new professor, she addresses him with informal 'you' 


\section{Author Query Form}

\section{Journal: Asian Journal of Social Psychology Article: ajsp_12133}

Dear Author,

During the copyediting of your paper, the following queries arose. Please respond to these by annotating your proofs with the necessary changes/additions.

- If you intend to annotate your proof electronically, please refer to the E-annotation guidelines.

- If you intend to annotate your proof by means of hard-copy mark-up, please use the standard proofing marks. If manually writing corrections on your proof and returning it by fax, do not write too close to the edge of the paper. Please remember that illegible mark-ups may delay publication.

Whether you opt for hard-copy or electronic annotation of your proofs, we recommend that you provide additional clarification of answers to queries by entering your answers on the query sheet, in addition to the text mark-up.

\begin{tabular}{|c|l|l|}
\hline Query No. & \multicolumn{1}{|c|}{ Query } & Remark \\
\hline Q1 & $\begin{array}{l}\text { AUTHOR: Please confirm that given names (red) and surnames/family names (green) } \\
\text { have been identified correctly. }\end{array}$ & \\
\hline Q2 & $\begin{array}{l}\text { AUTHOR: "Henrich, Heine, \& Norenzayan (2010)" is cited in text but not given in the } \\
\text { reference list. Please provide details in the list or delete the citation from the text. }\end{array}$ & \\
\hline Q3 & $\begin{array}{l}\text { AUTHOR: Please provide the city location of publisher for Reference Baumard, N., \& } \\
\text { Sperber, D. (2012). }\end{array}$ & \\
\hline Q4 & $\begin{array}{l}\text { AUTHOR: Please provide the city location of publisher for Reference Nucci, L. P. } \\
\text { (2001). }\end{array}$ & \\
\hline Q5 & AUTHOR: Please provide page range Smetana, J. (1993). & \\
\hline Q6 & $\begin{array}{l}\text { AUTHOR: Please provide the city location of publisher for Reference Sripada, C., \& } \\
\text { Stich, S. (2006). }\end{array}$ & \\
\hline
\end{tabular}


Required software to e-Annotate PDFs: Adobe Acrobat Professional or Adobe Reader (version 7.0 or above). (Note that this document uses screenshots from Adobe Reader $\mathrm{X}$ )

The latest version of Acrobat Reader can be downloaded for free at: http://get.adobe.com/uk/reader/

Once you have Acrobat Reader open on your computer, click on the Comment tab at the right of the toolbar:

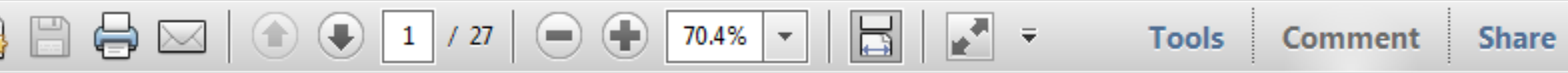

This will open up a panel down the right side of the document. The majority of tools you will use for annotating your proof will be in the Annotations section, pictured opposite. We've picked out some of these tools below:

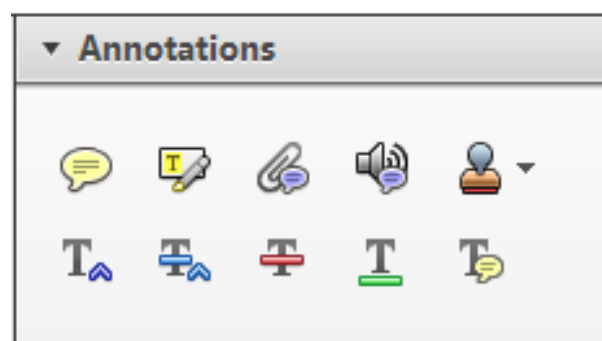

1. Replace (Ins) Tool - for replacing text.

Strikes a line through text and opens up a text box where replacement text can be entered.

How to use it

- Highlight a word or sentence.

- Click on the Replace (Ins) icon in the Annotations section.

- Type the replacement text into the blue box that appears.

Idard tramework for the analysis of $\mathrm{m}$ icy-Nevertheless, it also led to exog،

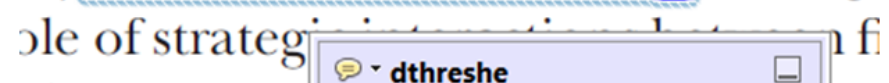
aber of comp 08/06/2011 15:58:17 is that the s1 nain compo: be level, are exc nc

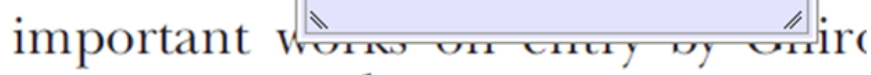
M heneferth) ${ }^{1}$ we anen the "hlarl $\mathrm{l}$

3. Add note to text Tool - for highlighting a section to be changed to bold or italic.

T Highlights text in yellow and opens up a text box where comments can be entered.

\section{How to use it}

- Highlight the relevant section of text.

- Click on the Add note to text icon in the Annotations section.

- Type instruction on what should be changed regarding the text into the yellow box that appears.

namic responses of mark ups ent with the VAR evidence

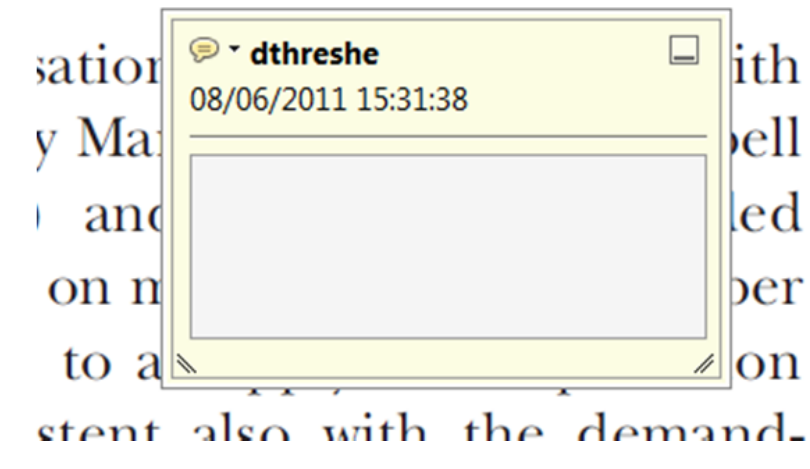

2. Strikethrough (Del) Tool - for deleting text.

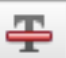

Strikes a red line through text that is to be deleted.

How to use it

- Highlight a word or sentence.

- Click on the Strikethrough (Del) icon in the Annotations section.

there is no room tor extra prohts al c ups are zero and the number of ret) values are not determined by Blanchard and Kiyotaki (1987), sfect competition in general equilil ts of aggregate demand and supply lassical framework assuming monol eph on evorenous number of firme

4. Add sticky note Tool - for making notes at specific points in the text.

Marks a point in the proof where a comment needs to be highlighted.

How to use it

- Click on the Add sticky note icon in the Annotations section.

- Click at the point in the proof where the comment should be inserted.

- Type the comment into the yellow box that appears.

iaisu airu suppiy sirucks. hivsl ui

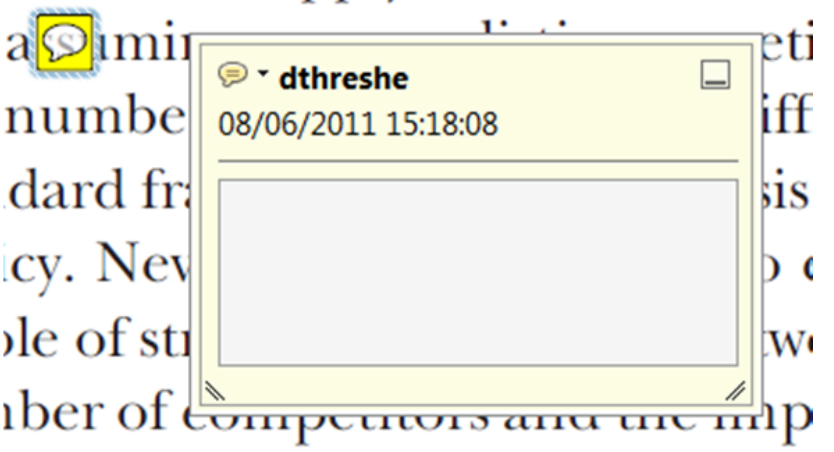

is that the structure of the secto. 
5. Attach File Tool - for inserting large amounts of text or replacement figures.

Inserts an icon linking to the attached file in the appropriate pace in the text.

How to use it

- Click on the Attach File icon in the Annotations section.

- Click on the proof to where you'd like the attached file to be linked.

- Select the file to be attached from your computer or network.

- Select the colour and type of icon that will appear in the proof. Click OK.

E N D

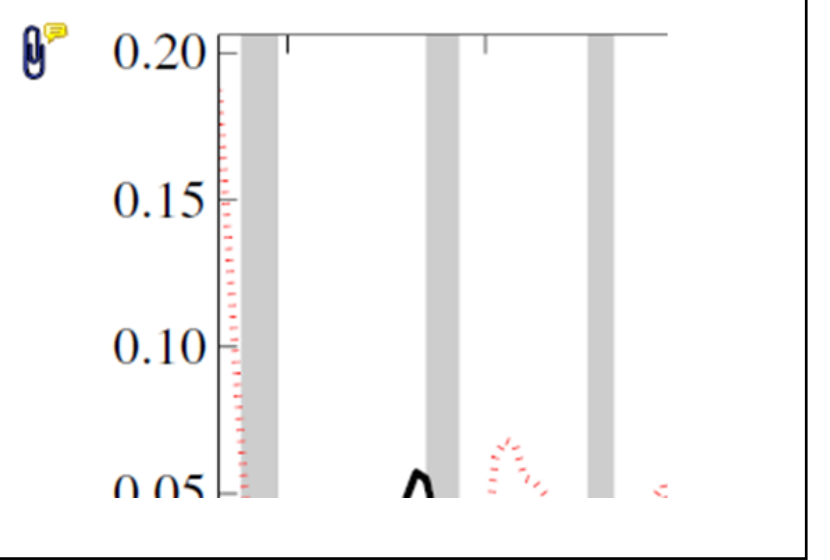

6. Add stamp Tool - for approving a proof if no corrections are required.

- Inserts a selected stamp onto an appropriate place in the proof.

\section{How to use it}

- Click on the Add stamp icon in the Annotations section.

- $\quad$ Select the stamp you want to use. (The Approved stamp is usually available directly in the menu that appears).

- Click on the proof where you'd like the stamp to appear. (Where a proof is to be approved as it is, this would normally be on the first page).

or the business cycie, starting with the on perfect competition, constant ret

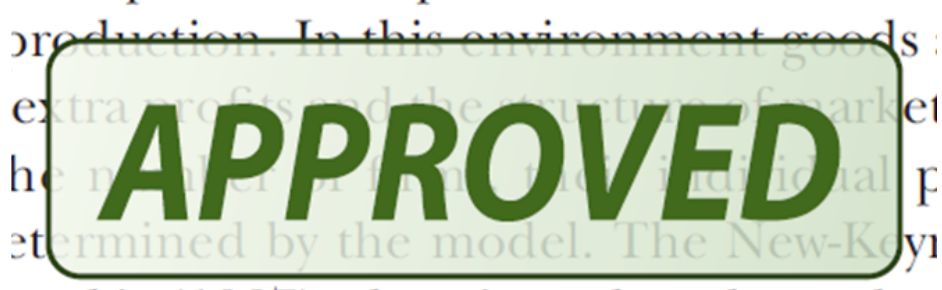
otaki (1987), has introduced produc general equilibrium models with nomin:

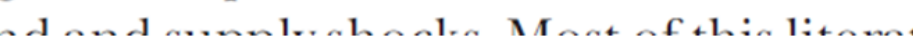

- Drawing Markups

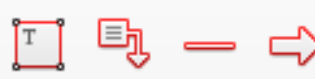

$0 \bigcirc \sqrt{6} \otimes$

\section{How to use it}

- Click on one of the shapes in the Drawing Markups section.

- Click on the proof at the relevant point and draw the selected shape with the cursor.

- To add a comment to the drawn shape, move the cursor over the shape until an arrowhead appears.

- Double click on the shape and type any text in the red box that appears.
7. Drawing Markups Tools - for drawing shapes, lines and freeform annotations on proofs and commenting on these marks.

Allows shapes, lines and freeform annotations to be drawn on proofs and for comment to be made on these marks.

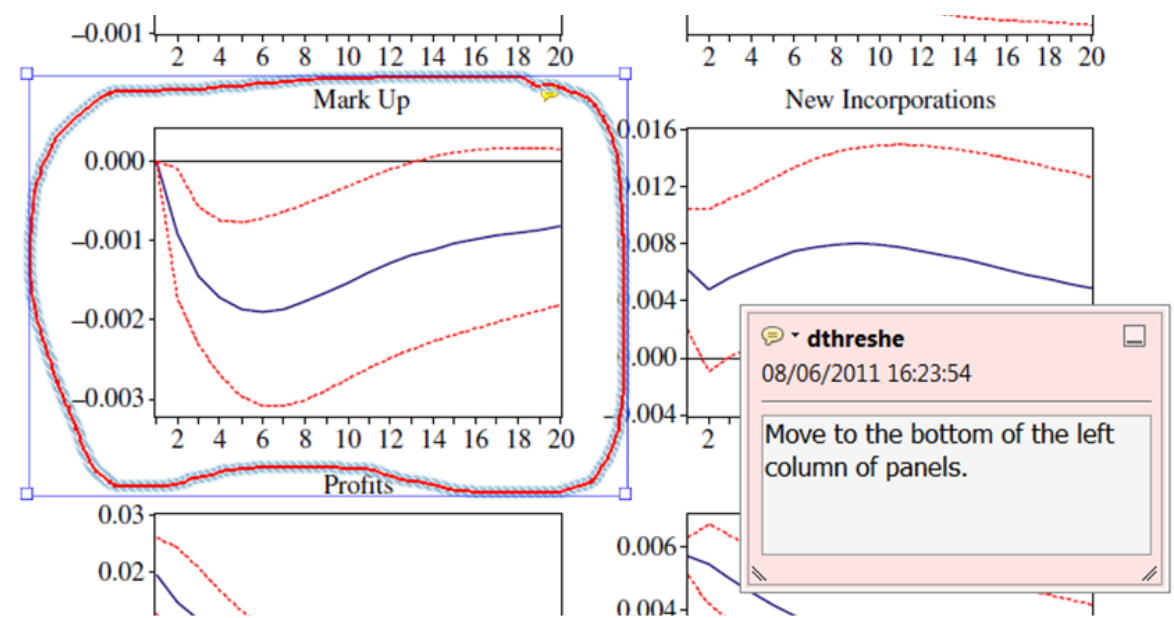

For further information on how to annotate proofs, click on the Help menu to reveal a list of further options:

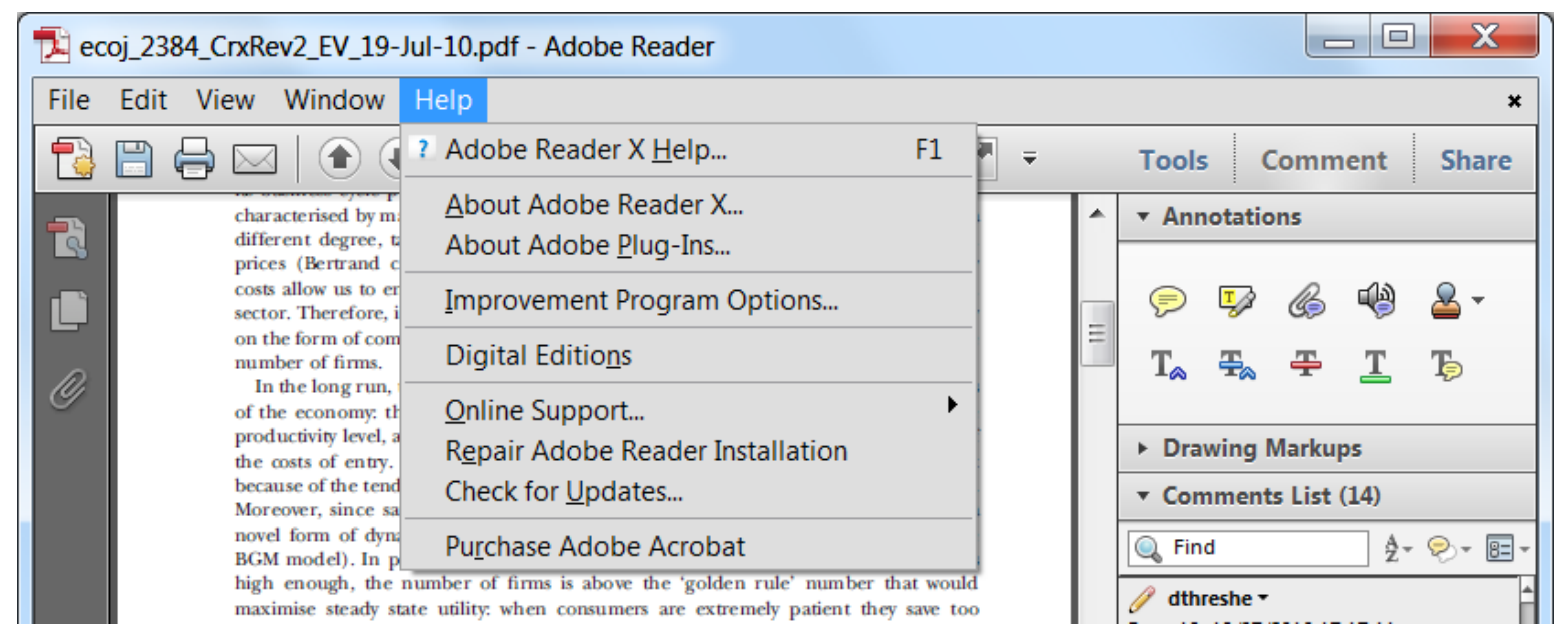

